\title{
Combined effects of structure and partial saturation in natural soils
}

\author{
Jean-Michel Pereira $^{\mathrm{a}, *}$, Mohamed Rouainia $^{\mathrm{b}}$ and Diego Manzanal ${ }^{\mathrm{a}}$ \\ ${ }^{a}$ Université Paris-Est, Laboratoire Navier (UMR 8205), CNRS, ENPC, IFSTTAR, Marne-la-Vallée, France \\ ${ }^{\mathrm{b}}$ School of Civil Engineering \& Geosciences, Newcastle University, Newcastle upon Tyne, UK
}

\begin{abstract}
The mechanical behaviour of natural clays is significantly affected by their in situ or initial structure in the form of cementation or interparticle bonding. This behaviour can differ substantially from the behaviour of reconstituted clays. Suction as well as plastic volumetric strains drive isotropic hardening/softening as this is a simple way to account for the phenomenon of volumetric collapse upon wetting and the stiffening effect that suction has on the soil skeletal response. A model that combines unsaturated and structured behavior is presented and then used to simulate stress strain behaviour observed for an unsaturated natural clay subjected to isotropic load paths. A parametric analysis is performed to observe the influence suction hardening has on mobilized strengths. It is also shown that the model can predict the maximum of collapse of unsaturated soils.
\end{abstract}

Keywords: Elastoplasticity, unsaturated soils, suction, effective stress, cemented soils

\section{Introduction}

The majority of research and analysis in soil mechanics to date has assumed full saturated conditions, not least because this simplifies the development of analytical, physical and numerical models. Similarly, the mechanics of structured soils, whose behaviour is influenced by physico-chemical effects at the level of interparticle bonds, is relatively well understood, despite a growing appreciation of the importance of structure in natural soils. In recent years, researchers have begun to look at the modelling of both of these difficult features of real soils, namely partial saturation and structure, and to develop constitutive models that can be used to predict engineering behaviour more realistically in situations where the standard models are known to be inadequate. Saturated models, for example, cannot predict the sudden collapse of a slope due to rainfall infiltration; and standard elasto-plastic models cannot predict the irrecoverable degradation of strength and stiffness that is observed when natural soils are deformed. In saturated conditions, Terzaghi [1] suggested that the mechanical response of a soil depends only on the effective stress tensor

$$
\sigma^{\prime}=\sigma-u \iota
$$

where $\sigma$ is the total continuum stress tensor, $u$ is the (liquid) pore pressure, and $\iota$ is the identity tensor. In seeking a generalisation of this principle to partially saturated states, it was initially supposed that both the state of deformation and the failure strength of unsaturated soils might be determined by a suitable generalised effective stress [2]. It was soon realised that that could not, by itself, explain the phenomenon of collapse upon wetting [3], and this led some to doubt the value of the effective stress principle in unsaturated conditions altogether. It was later recognised

\footnotetext{
*Corresponding author: Jean-Michel Pereira, Université Paris-Est, Laboratoire Navier (UMR 8205), CNRS, ENPC, IFSTTAR, F-77455 Marne-la-Vallée, France. E-mails: jeanmichel.pereira@enpc.fr (Jean-Michel Pereira); m.rouainia@newcastle.ac.uk (Mohamed Rouainia); diego.manzanal@enpc.fr (Diego Manzanal).
} 
that surface tension forces exert a stabilising influence on the soil fabric, and contribute significantly to the strenght of unsaturated soils [4]. A multi-phase continuum analysis (Fredlund and Morgenstern, [5] shows that any three known pressures, either the total pressure $p$, the water pressure $u_{\mathrm{L}}$, or the air pressure $u_{\mathrm{G}}$, may be treated as a reference pressure. Thus, with $u_{\mathrm{G}}$ as a reference pressure, the stress state of an unsaturated soil can be represented by the net stress tensor $\sigma^{\text {net }}=\sigma-u_{\mathrm{G}} \boldsymbol{l}$, and the suction $s=u_{\mathrm{G}}-u_{\mathrm{L}}$. The essential point is that unsaturated soils have an additional degree of freedom compared to saturated soils, and a full description of their state requires a second, independent kinetic variable (e.g. s), regardless of whether $\boldsymbol{\sigma}^{\text {net }}$ or $\boldsymbol{\sigma}^{\prime}$ is chosen as the constitutive stress tensor. In consideration of the influence of suction on strength, most previous modelling studies focused on the generalisation of the isotropic hardening variable of the underlying saturated model. The first full constitutive model for unsaturated soils [6], known as the Barcelona Basic Model (BBM), was based on the modified Cam-clay (MCC) model, whose isotropic hardening variable is the effective consolidation pressure $p_{0}^{\prime}$. The BBM was formulated in the stress space $\left(\boldsymbol{\sigma}^{\text {net }}, s\right)$ and it included suction hardening by generalising the definition of $p_{0}^{\prime}$ to account for the influence of $s$. Wheeler and Sivakumar [7] suggested that the specific water content $v_{\mathrm{w}}$ is a more appropriate kinematic state variable than the degree of saturation $S_{\mathrm{r}}$, because $\dot{v}_{\mathrm{w}} / v$ (where $v$ is the specific volume) is power conjugate to $s$. Houlsby [8], on the other hand, derived an alternative set of work-conjugate stress variables retaining the more natural kinematic variables $\left(\boldsymbol{\epsilon}, S_{\mathrm{r}}\right)$, consisting of: $i$ ) the generalised effective stress $\sigma^{\prime}$, defined in terms of the equivalent pore pressure:

$$
u=S_{\mathrm{r}} u_{\mathrm{L}}+\left(1-S_{\mathrm{r}}\right) u_{\mathrm{G}}
$$

and ii) the modified suction $n s$, where $n$ stands for porosity. Bolzon et al. [9] developed an unsaturated model, based on a generalised plasticity model for saturated soils, that was formulated in terms of $\left(\sigma^{\prime}, s\right)$. The advantages of using $\sigma^{\prime}$ (rather than $\sigma^{\text {net }}$ ) as a constitutive stress are now widely accepted [10], and several recent studies have pursued this approach [11-14]. The choice of stress variables has nevertheless been the subject of much debate [15-17].

Constitutive models for unsaturated soils require an additional equation relating changes in $s$ to changes in $S_{\mathrm{r}}$, just as $\dot{\boldsymbol{\sigma}}^{\prime}$ is related to $\dot{\boldsymbol{\epsilon}}$ in saturated models. This equation describes the water retention properties of the material which are in general strongly coupled to the mechanical behaviour. For monotonic (wetting or drying) processes, a single water retention curve is sufficient for modelling purposes. In general, however, the suction-saturation relationship is hysteretic, and $S_{\mathrm{r}}$ cannot be expressed simply as a function of state. The significance of hydraulic hysteresis in geotechnical problems is a subject of increasing research interest. Techniques have recently been established for the inclusion of its effects in constitutive models (see for instance [18, 19]). Wheeler and co-workers [20] have developed a conceptual model to explain the phenomenon of hysteresis in terms of the structure of the pore space.

Natural soils typically exhibit a significant inherent anisotropy of fabric. They are further distinguished by the presence of inter-particle bonding, which contributes to their strength and stiffness [21]. The combined effects of fabric and bonding will be referred to using the term structure in this paper. There have been considerable advances in the constitutive modelling of natural soils to account for structure, and damage to structure, with a single yield locus elasto-plastic framework (e.g. [22, 23]), and more recently, using the framework of kinematic hardening and bounding surface plasticity [24-26]. These models converge on the MCC model in the limit of total destructuration. They employ an additional isotropic hardening variable, namely the degree of structure, in combination of $p_{0}^{\prime}$, to model the enhanced strength of a structured soil, relative to a reconstituted soil at the same void ratio.

The combined effects of bonding and partial saturation were considered by Alonso and Gens [27]. It was predicted that these combined effects would result in an increase in yield stress that is larger than the sum of the individual contributions. This was confirmed by Leroueil and Barbosa [28], who conducted experiments on an unsaturated saprolite from Brazilian gneiss, artificially bonded with cement (see Fig. 1). The question of how to model this suction-structure interaction by generalizing the definition of the effective $p_{0}^{\prime}$, has only recently been considered by e.g. [29-35]. Most of these advanced models account for a double structure, defined by micro- and macro-scale porosities.

In the following, a relatively simple model accounting for structure and partial saturation in soils is proposed. This model is aimed at capturing the coupled effects of these features on the macroscopic behaviour of natural soils. 


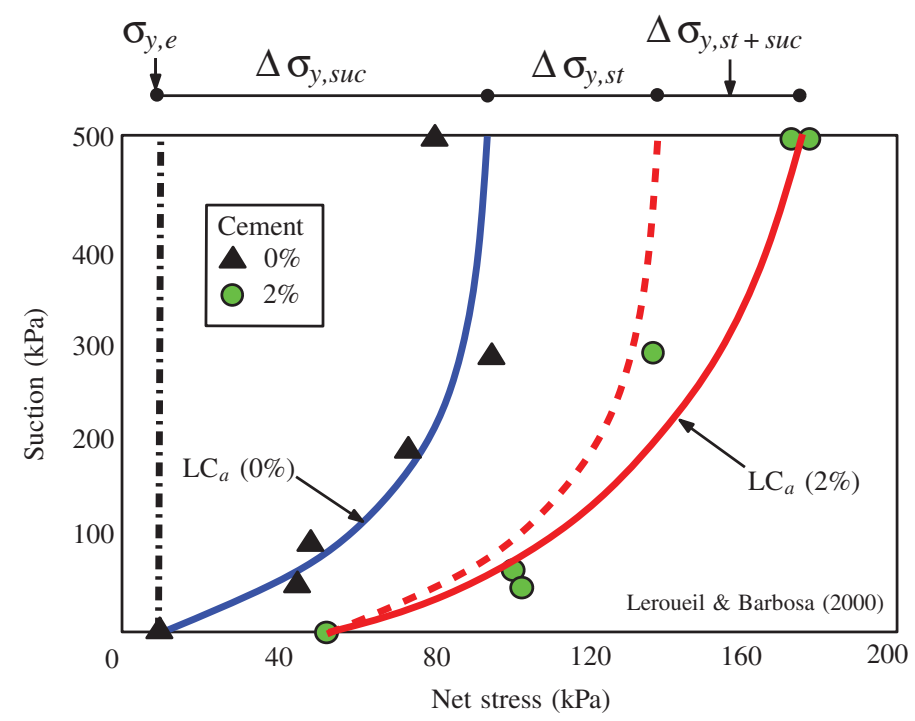

Fig. 1. Evolution of the yield stress as a function of suction in the case of an artificially cemented soil (after [28]).

\section{Constitutive modelling}

\subsection{Choice of stress variables}

Attention is restricted to small deformation regime, isothermal conditions and the rate-independent behaviour. Thus, the basic elasto-plastic assumption is the additive decomposition of the strain rate, $\dot{\epsilon}$, into an elastic and a plastic part, $\dot{\epsilon}^{e}$ and $\dot{\epsilon}^{p}$, respectively:

$$
\dot{\epsilon}=\dot{\epsilon}^{e}+\dot{\epsilon}^{p}
$$

The effective pressure is $p^{\prime}=p-u$, where $p$ is the total pressure and $u$ is the equivalent pore pressure. Following an energetic approach, Coussy \& Dangla ([36]) proposed the following relation, accounting for the energy of the interfaces that separate the liquid and gas phases:

$$
u=u_{\mathrm{G}}-S_{\mathrm{r}} s-\frac{2}{3} U\left(S_{\mathrm{r}}, \phi\right)
$$

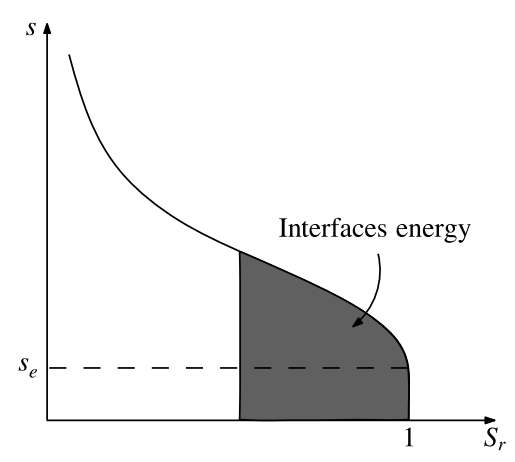

Fig. 2. Water retention curve and interface energy. 
where $\phi$ is the porosity and $U\left(S_{r}, \phi\right)$ corresponds to the interfaces energy (see Fig. 2 for a schematic representation of the relationship between interfaces energy and the water retention curve) and is given by:

$$
U\left(S_{r}, \phi\right)=\int_{S_{r}}^{1} s\left(S_{r}, \phi\right) d S_{r}
$$

The coefficient 2/3 appearing in Equation (4) takes account of the effects of skeleton deformation (via porosity changes) on the water retention properties of the soil.

\subsection{Constitutive stress-strain equations}

\subsubsection{Modelling unsaturation effects}

According to the framework described in [13], the stress defined by Equation (1) together with the equivalent pore pressure defined by Equation (4) can be used instead of Terzaghi's effective stress to extend elastoplastic models to unsaturated states.

Starting from the Modified Cam-Clay model, the constitutive stress-strain equations of the model presented in this paper are summarized hereafter. For simplicity, the model formulation is expressed in triaxial stress space. The elastic law is represented by the incremental elastic-strain/stress equations:

$$
\begin{aligned}
d \epsilon_{v}^{e} & =\frac{\kappa}{v} \frac{d p^{\prime}}{p^{\prime}} \\
d \epsilon_{q}^{e} & =\frac{d q}{3 G}
\end{aligned}
$$

where $\epsilon_{v}^{e}$ and $\epsilon_{q}^{e}$ are the volumetric and shear components of the elastic strain tensor, $v$ is the specific volume, and $\kappa$ and $G$ are material constants. The yield function is given by:

$$
f\left(p^{\prime}, q, p_{0}^{\prime}\right) \equiv q^{2}-M^{2} p^{\prime}\left(p_{0}^{\prime}-p^{\prime}\right)=0
$$

where $M$ is a material constant and $p_{0}^{\prime}$ represents the (generalized) hardening parameter of the model, which can be seen as an apparent consolidation pressure. It accounts not only for the (classical) mechanical hardening arising from irreversible volumetric strains but also for the suction-induced (apparent) hardening.

The remaining ingredient to complete the unsaturated elastoplastic framework is the definition of the hardening due to suction. This feature, which is a key point in the modelling of unsaturated soil behaviour, accounts for an additional role of suction on the strength of the soil (apart from its contribution to static equilibrium). This function corresponds to the well-known Loading-Collapse (LC) curve of the Barcelona Basic Model (BBM, [6]). The identification of this relation may be achieved by using a direct comparison to the LC curve of the BBM using the following relation:

$$
p_{0}^{\prime}=\bar{p}_{0}+u_{\mathrm{G}}-u
$$

This expression is obtained by equating the total preconsolidation pressures expressed in terms of effective stress (Equation 1) and net stress $\sigma^{\text {net }}=\sigma-u_{\mathrm{G}} \boldsymbol{\iota} . \bar{p}_{0}$ is the net preconsolidation pressure as defined in the BBM:

$$
\bar{p}_{0}=p^{c}\left(\frac{\bar{p}_{0}^{*}}{p^{c}}\right)^{\frac{\lambda(0)-\kappa}{\lambda(s)-\kappa}}
$$

where $p^{c}$ is a reference pressure and $\lambda(s)$ is given by:

$$
\lambda(s)=\lambda(0)[r+(1-r) \exp (-\beta s)]
$$

where $\lambda(0)$ is the slope of the virgin compression line at saturation in the net stress-specific volume plane, $r$ is the fraction of $\lambda(0)$ corresponding to the slope of the virgin compression line of the material under high suctions in the net stress-specific volume plane and $\beta$ is a material parameter linked to the rate of change of the soil compressibility 
with suction. Alternatively, one can also give directly an explicit functional definition of the apparent hardening due to suction:

$$
p_{0}^{\prime}=p_{0}^{*} l(s)
$$

where $p_{0}^{\prime *}$ is the effective preconsolidation pressure under saturated conditions and at the same plastic strain state than the effective preconsolidation pressure $p_{0}^{\prime}$ at the current unsaturated state. In this case, the identification of the $l(s)$ function should be based on experimental data on the evolution of the apparent yield locus with respect to changes in suction (or degree of saturation).

It is worth noting that other choices are possible for the expression of the preconsolidation pressure as a function of the saturation state. However, it is easy to show [37] that the one given in equation (12) ensures that

$$
\frac{d p_{0}^{\prime}}{p_{0}^{\prime}}=\frac{d p_{0}^{\prime *}}{p_{0}^{\prime *}}
$$

as is the case in the BBM. It should be noted that the $l(s)$ function may be expressed in terms of the degree of saturation $S_{r}$ instead of the suction $s$. This may induce some advantages in terms of numerical modelling (concerning transitions between saturated and unsaturated conditions). In terms of consistency, this latter approach (already used by several authors, see for instance $[10,38]$ ) presents the advantage to include in the arguments of the function describing the effective preconsolidation pressure $p_{0}^{\prime}$ (see Equation (12)) two variables of the same thermodynamical nature, namely $\varepsilon_{v}^{p}$ and $S_{r}$ which are both generalized strains. Here, two expressions are considered:

$$
\begin{aligned}
& l\left(S_{r}\right)=1+\frac{k}{p_{a t m}}\left(s\left(S_{r}\right) S_{r}-s_{e}\right) \\
& l\left(S_{r}\right)=1+a \tanh \left(\frac{b}{p_{a t m}}\left(s\left(S_{r}\right)-s_{e}\right)\right)
\end{aligned}
$$

where $p_{a t m}$ is a reference pressure and $s_{e}$ is the air entry suction, and $k, a$ and $b$ are are material constants for a given soil. The mechanical hardening rule does not depend on the $l\left(S_{r}\right)$ function (see Equation (13)) and can classically be expressed as follows:

$$
\frac{d p_{0}^{\prime *}}{p_{0}^{* *}}=\frac{v}{\lambda-\kappa} d \epsilon_{v}^{p}
$$

\subsubsection{Including structure effects}

As mentioned previously, structure and partial saturation contributions to the apparent yield stress are coupled in the sense that the LC curve of a cemented material is neither a simple translation of the uncemented LC curve nor an homothetic transformation of it (see Fig. 1). This point is clearly observable in Figs. 3 and 4. When inspecting the LC curves in terms of yield stress normalised with respect to the saturated stress, it can be concluded that the relative contribution of suction to the yield stress diminishes for increasing cement content. The reason for this observation is that capillary forces that contribute to interparticle efforts (and thus increase soil's strength) tend to become negligible if the soil's intrinsic stiffness increases (which occurs when the cement content increases). A schematic representation of these coupled effects is presented in Fig. 5.

To reproduce these observations, and following [24], a scalar parameter $R \geq 1$ is introduced as a measure of the degree of structure of the material. This parameter is supposed to degrade from its initial value to unity as the material deforms and loses its initial structure. Starting from the saturated net preconsolidation pressure of the equivalent remoulded or uncemented soil $\bar{p}_{0}^{*}$, the apparent preconsolidation pressure of the structured soil is $R \bar{p}_{0}^{*}$ at saturation, and for a given value of suction it is given by:

$$
\bar{p}_{0}=p^{c}\left(\frac{R \bar{p}_{0}^{*}}{p^{c}}\right)^{\frac{\lambda(0)-\kappa}{\lambda(s)-\kappa}}
$$




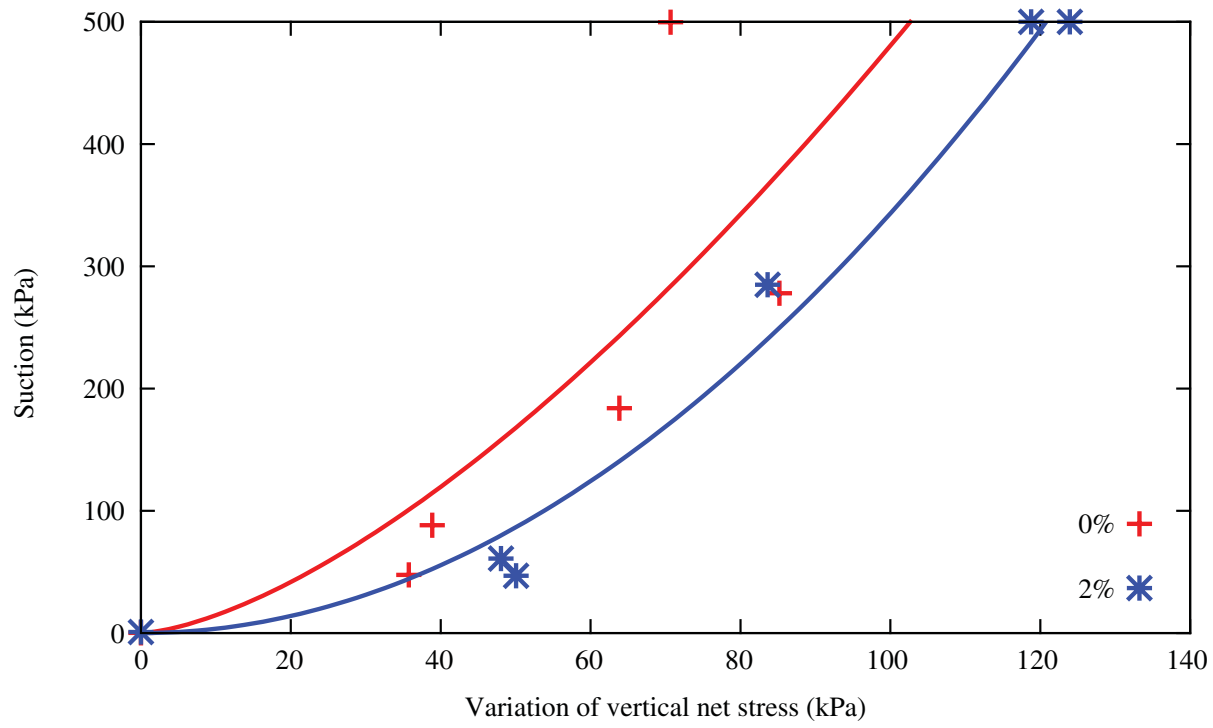

(a) Yield stress variation with respect to saturated state

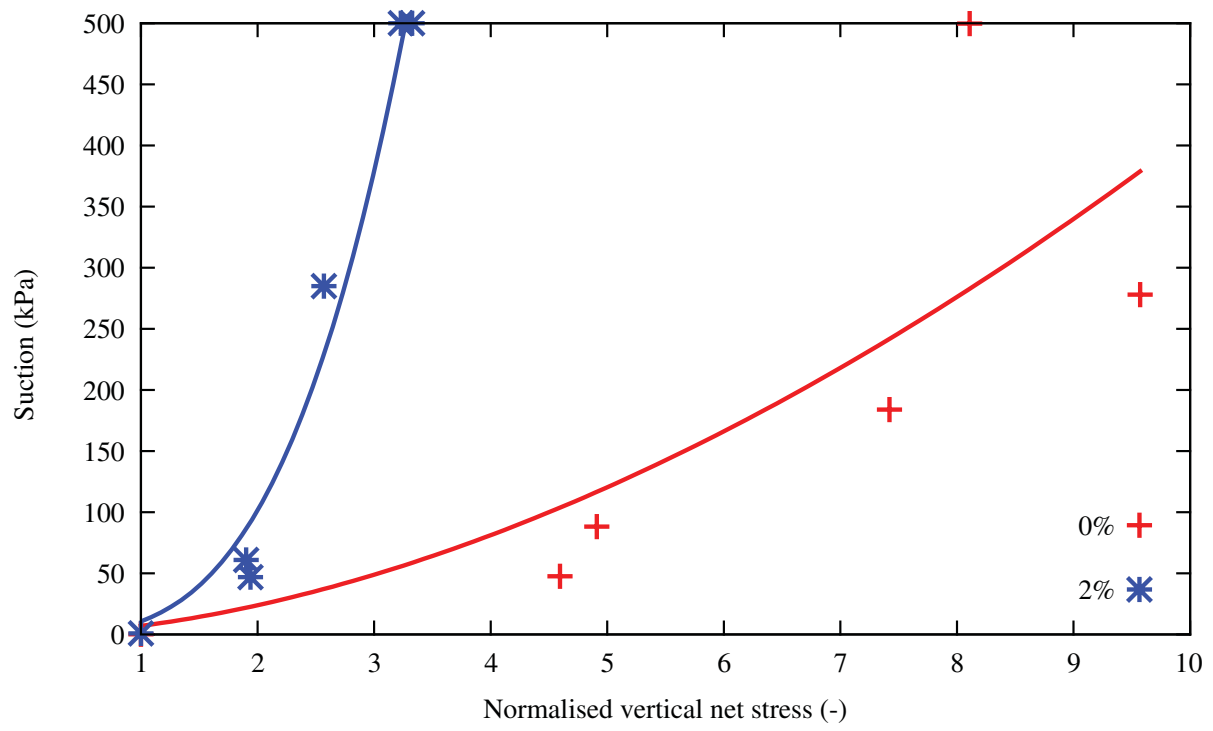

(b) Yield stress normalised with respect to saturated state

Fig. 3. Coupled effects of suction and cement ratio (data from [28]). Curves represent a best fit using a power law.

Other possibilities exist. For instance, if the alternative choices to the LC curve of BBM hereinabove mentioned (equations (14) and (15)) are used, the following expressions for the effective preconsolidation pressure are obtained (see Fig. 6):

$$
\begin{aligned}
& p_{0}^{\prime}(s)=R p_{0}^{\prime *} l\left(S_{r}\right)=R p_{0}^{\prime *}\left[1+\frac{k}{p_{a t m}}\left(s S_{r}-s_{e}\right)\right] \\
& p_{0}^{\prime}(s)=R p_{0}^{\prime *}\left[1+a \tanh \left(\frac{b}{p_{a t m}}\left(s-s_{e}\right)\right)\right]
\end{aligned}
$$




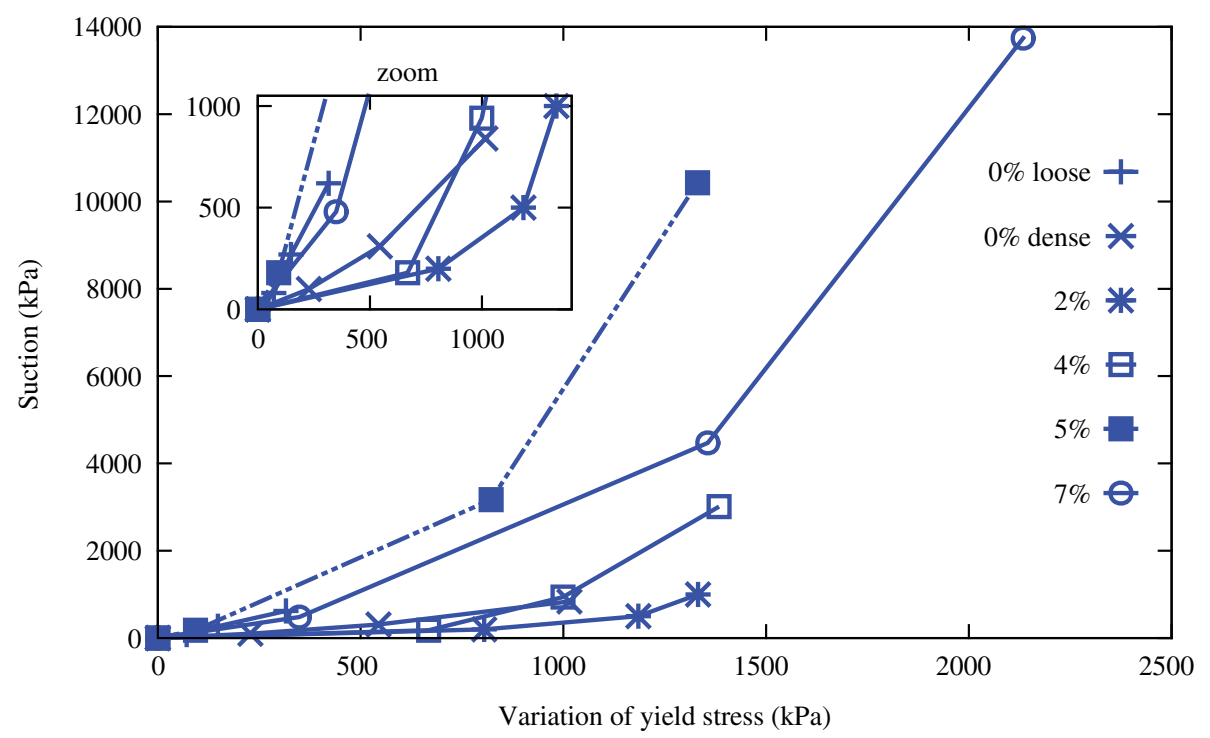

(a) Yield stress variation with respect to saturated state

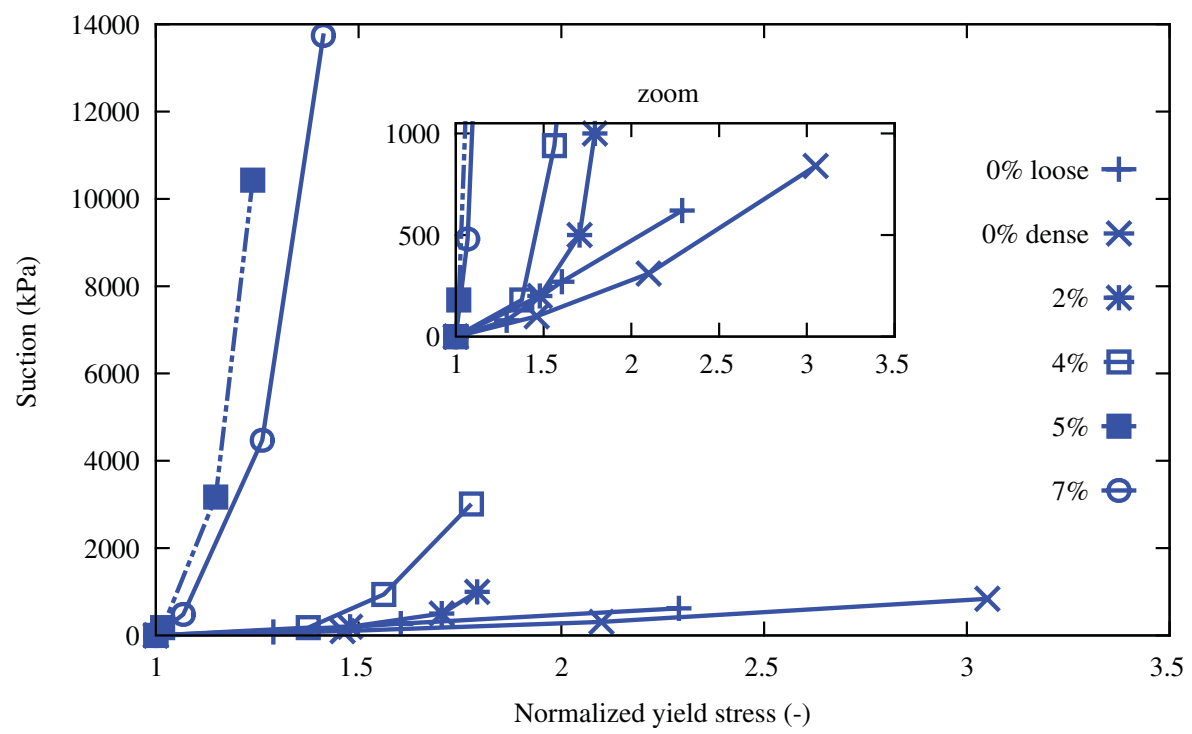

(b) Yield stress normalised with respect to saturated state

Fig. 4. Coupled effects of suction and cement ratio on normalised yield stress (data from [46]. Curves represent a best fit using a power law.

The rate of degradation of the soil structure is also assumed to be saturation dependent and given by:

$$
d R=-k\left(S_{r}\right) \frac{R-1}{\lambda(0)-\kappa} d \varepsilon_{d}
$$

where $d \varepsilon_{d}$ is a measure of the incremental irreversible deformation (including both volumetric and shear strains):

$$
d \varepsilon_{d}=\sqrt{(1-A)\left(d \epsilon_{v}^{p}\right)^{2}+A\left(d \epsilon_{q}^{p}\right)^{2}}
$$




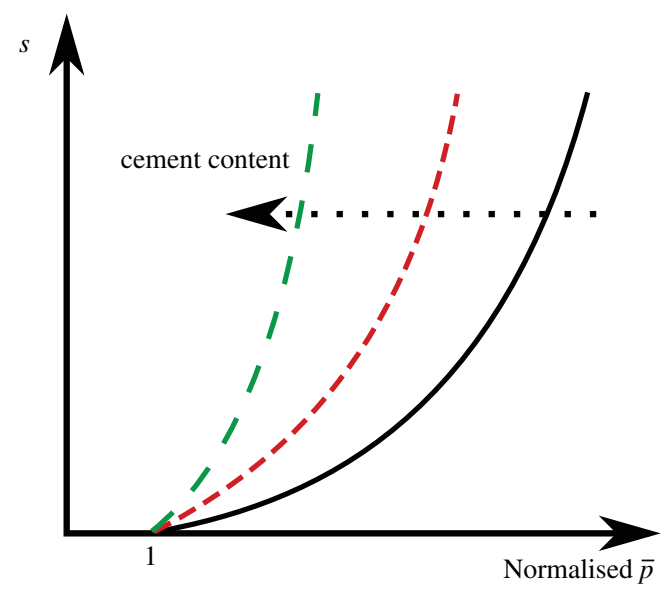

Fig. 5. Schematic representation of cement ratio effects on the normalised LC curve.

with $A$ a material constant. Without further indication on the effective couplings between structure and partial saturation effects, the structure degradation function, $k\left(S_{r}\right)$, is assumed to have the following form:

$$
k\left(S_{r}\right)=k_{0}\left(\frac{p_{0}^{\prime *}}{p_{0}^{\prime}}\right)^{\psi}
$$

where $k_{0}$ is a material parameter representative of structure degradation under saturated conditions and $\psi$ is a material parameter that determines the effect of partial saturation on the rate of degradation via the ratio between the saturated and unsaturated preconsolidation pressures. The modified preconsolidation stress as defined in Equations (9) and (17) (or alternatively in equations (18) or (19)) is then included in the yield function (Equation (8)). Invoking the consistency condition gives:

$$
\frac{\partial f}{\partial p^{\prime}} d p^{\prime}+\frac{\partial f}{\partial q} d q+\frac{\partial f}{\partial p_{0}^{\prime}} d p_{0}^{\prime}=0
$$

Expanding the last term in (23) gives:

$$
\frac{\partial f}{\partial p^{\prime}} d p^{\prime}+\frac{\partial f}{\partial q} d q+\frac{\partial f}{\partial p_{0}^{\prime}} \frac{\partial p_{0}^{\prime}}{\partial \epsilon_{v}^{p}} d \epsilon_{v}^{p}+\frac{\partial f}{\partial p_{0}^{\prime}} \frac{\partial p_{0}^{\prime}}{\partial s} d s+\frac{\partial f}{\partial p_{0}^{\prime}} \frac{\partial p_{0}^{\prime}}{\partial R} d R=0
$$

Accounting for the hardening function (13), the plastic deformation increment may formally be written as:

$$
d \epsilon^{p}=\Lambda_{1} d \boldsymbol{\sigma}^{\prime}+\Lambda_{2} d s \iota+\Lambda_{3} d R \boldsymbol{\iota}
$$

which shows the three possible (and coupled) mechanisms involved in the generation of plastic strains where $\Lambda_{1}$, $\Lambda_{2}$ and $\Lambda_{3}$ are hardening functions.

\subsection{Modelling the water retention properties}

In a first step, the water retention properties of the soil will be modelled using Brooks \& Corey's model (see [39]):

$$
S_{r}=\left(\frac{s_{e}}{s}\right)^{\alpha}
$$

where $s_{e}$ and $\alpha$ are model parameters related to the air entry value and the slope of the retention curve in a $\left(\ln \left(S_{r}\right), \ln (s)\right)$ plane. This equation does not include hysteresis effects. It can be seen as the description a main branch (either drying or wetting) of the water retention curve if monotonic changes of water content are to be 


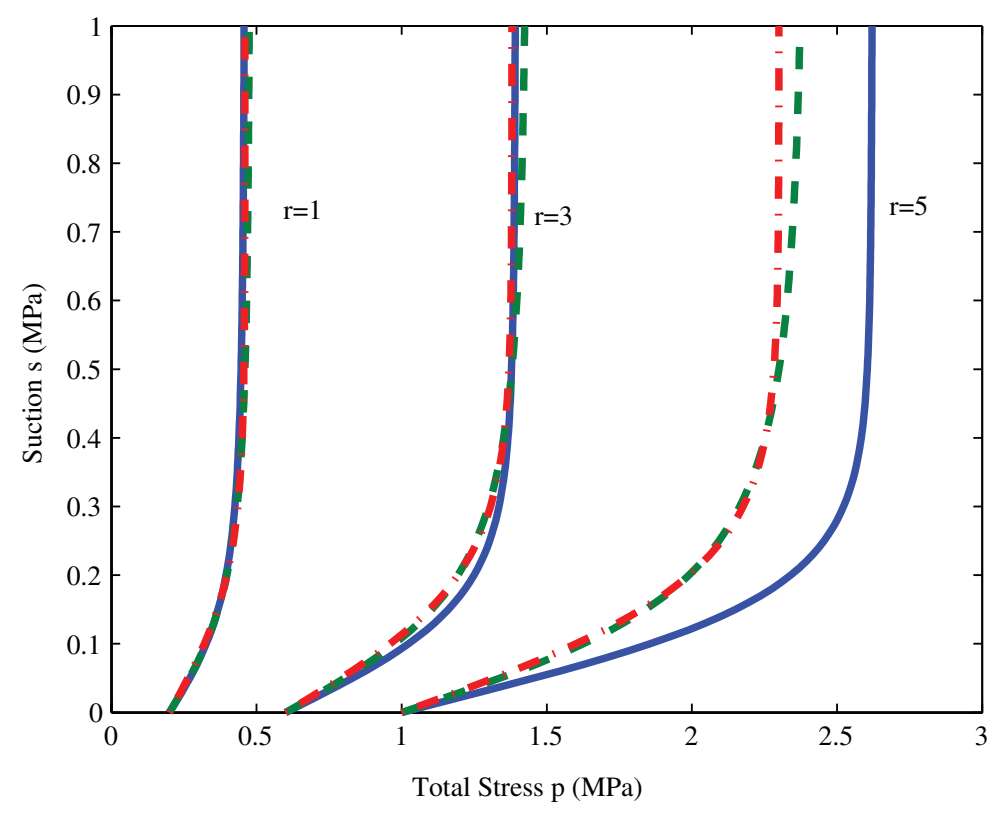

Fig. 6. Illustrative simulated LC loci: coupled influence of suction and structure effects for different choices of the LC curves, as expressed by Equation (17): continuous lines, Equation (18): dashed lines and Equation (19): dash-dotted lines.

accounted for. Furthermore, Equation (26) assumes no coupled effects of soil deformation (porosity changes for instance) on the water retention curve.

\subsection{Identification of model parameters}

Identification of the parameters of the model is a key point. The aim of the present model is to add as less as possible new parameters with respect to the Barcelona Basic Model (BBM). The existing parameters originating from Modified Cam-Clay Model (MCC) are: $\lambda, \kappa, M, N$ (or initial void ratio) and $p_{0}^{\prime *}$. In addition, the parameters coming from BBM to account for unsaturation effects are: $\beta, p^{c}$ and $r$. The full description of these latter effects requires the definition of the water retention properties, which is not included in the original BBM. This is done here by using 2 additional parameters: $s_{e}$ and $\alpha$. Finally, structure effects are described using 4 parameters: $R_{0}, k_{0}$, $A$ and $\psi$, where $R_{0}$ is the initial degree of structure. These parameters are present in the original contribution of Rouainia \& Muir Wood [24]. It should be noted that particular attention has been taken in order to avoid including specific parameters devoted to the coupling effects between saturation and structure although these coupling effects are included in the present model formulation through the dependence (on $R$ and $s$ ) of the hardening functions $\Lambda_{1}$, $\Lambda_{2}$ and $\Lambda_{3}$ in (Equation (25)).

Among the parameters newly introduced with respect to $\mathrm{BBM}, R_{0}$ has a straightforward physical meaning and can be deduced from common laboratory tests performed on structured and remoulded soils. The others $\left(k_{0}, A\right.$ and $\psi)$ will require an estimation based on a comparison of model predictions with experimental measurements.

One of the main difficulties is the discrimination between the effects of structure and partial saturation on the yield locus in the $\left(p^{\prime}, s\right)$ (or equivalently $\left.(\bar{p}, s)\right)$ plane. In practice, experimental data (typically isotropic compressions) on saturated material on both intact and reconstituted samples would be sufficient to characterize the structure effects on the studied soil without the coupled influence of partial saturation effects (remember that the scalar parameter describing the degree of structure has been defined in this study as an apparent over-consolidation of the intact material with respect to the remoulded material, both at saturated state). One of the advantages of this procedure is that it involves simple tests on saturated reconstituted specimens which are more easily reproducible. 


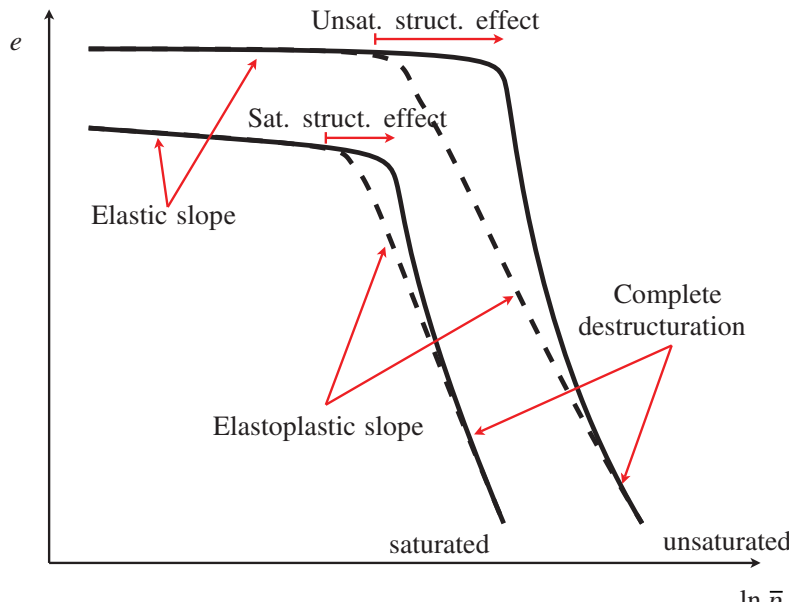

Fig. 7. Schematic representation of isotropic behaviour of saturated and unsaturated structured soils.

To close the identification of the overall hardening function, a common procedure is then required which consists in determining the yield point of intact samples at various levels of suction. Doing so will of course give an idea of the couplings that may appear between partial saturation and structuration effects (see Figs. 3 and 4 and the corresponding discussion). In complement, a schematic representation of the coupled effects between structure and partial saturation is given in Fig. 7.

\section{Model performance}

The proposed constitutive model has been implemented into a constitutive driver in order to test its capabilities at the stress point level. Some simulations of theoretical tests and comparisons with available experimental data are presented hereafter. The model parameters used in this section are summarised in Table 1.

\subsection{Illustration of model capabilities}

Figures 8 and 9 illustrate the influence of initial suction and degree of structure on the oedometric response of a virtual unsaturated structured soil. Figure 8 shows constant suction oedometer tests on a soil starting from different

Table 1

Model parameters

\begin{tabular}{lcc}
\hline Parameter & Virtual soil & Brazilian soil \\
\hline$\kappa(-)$ & 0.02 & 0.015 \\
$\lambda(0)(-)$ & 0.2 & 0.055 \\
$\nu(-)$ & 0.3 & 0.3 \\
$M(-)$ & 1.0 & N.A. \\
$\beta\left(\mathrm{kPa}^{-1}\right)$ & 0.0123 & 0.01 \\
$r(-)$ & 0.75 & 0.98 \\
$p^{c}(\mathrm{kPa})$ & 100.0 & 0.001 \\
$s_{e}(\mathrm{kPa})$ & 1.0 & 0.55 \\
$\alpha(-)$ & 2.5 & 8.57 \\
$A(-)$ & 0.75 & 0.0 \\
$k_{0}(-)$ & 5.0 & 1.5 \\
$\psi(-)$ & 0.1 & 0.1 \\
$p_{0}^{*}(\mathrm{kPa})$ & 200.0 & 80.0 \\
$e_{0}(-)$ & 0.9 & 0.7 \\
$R_{0}(-)$ & N.A. & 2.0 \\
\hline
\end{tabular}




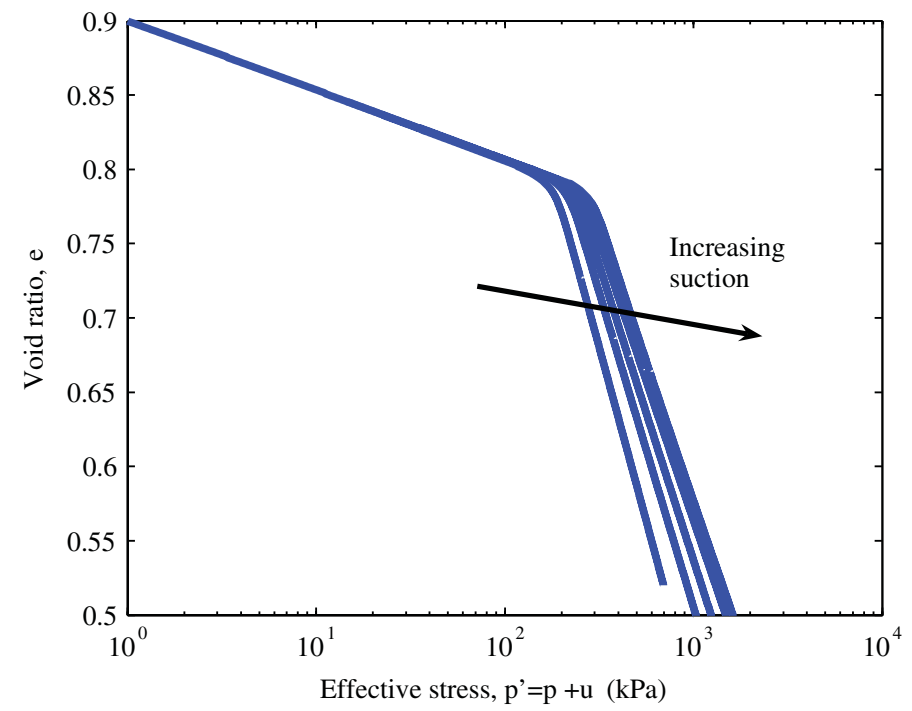

Fig. 8. Influence of initial suction value on oedometer response of a virtual unstructured soil: constant suction compressions $(s=$ $\left.\{1,50,100,200,500\} \mathrm{kPa}, R_{0}=1\right)$.

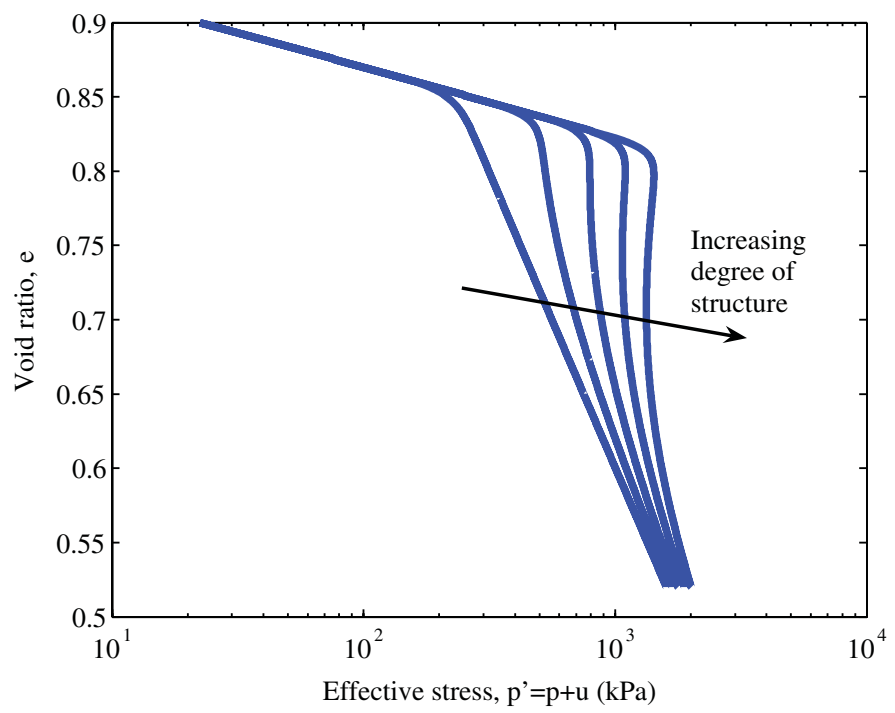

Fig. 9. Influence of the initial degree of structure on oedometer response of a virtual soil: constant suction compressions $(s=100 \mathrm{kPa}$, $\left.R_{0}=\{1,2,3,4,5\}\right)$.

values of suction. The modelling of initial degree of structure and its degradation has been disabled, simply by fixing the initial degree of structure to unity. The classical trends of unsaturated compacted soils behaviour are observed: increase of yield stress and decrease of compressibility with increasing suction.

Figure 9 highlights the role of the initial degree of structure on the simulations. Soils presenting a higher initial degree of structure are characterized by a higher apparent yield point and an increasing trend to brittle behaviour. At high stresses, corresponding to considerable degradation of the initial structure, the curves of initially structured soils $\left(R_{0}=\{2,3,4,5\}\right)$ tend to converge towards that of unstructured materials $\left(R_{0}=1\right)$. 


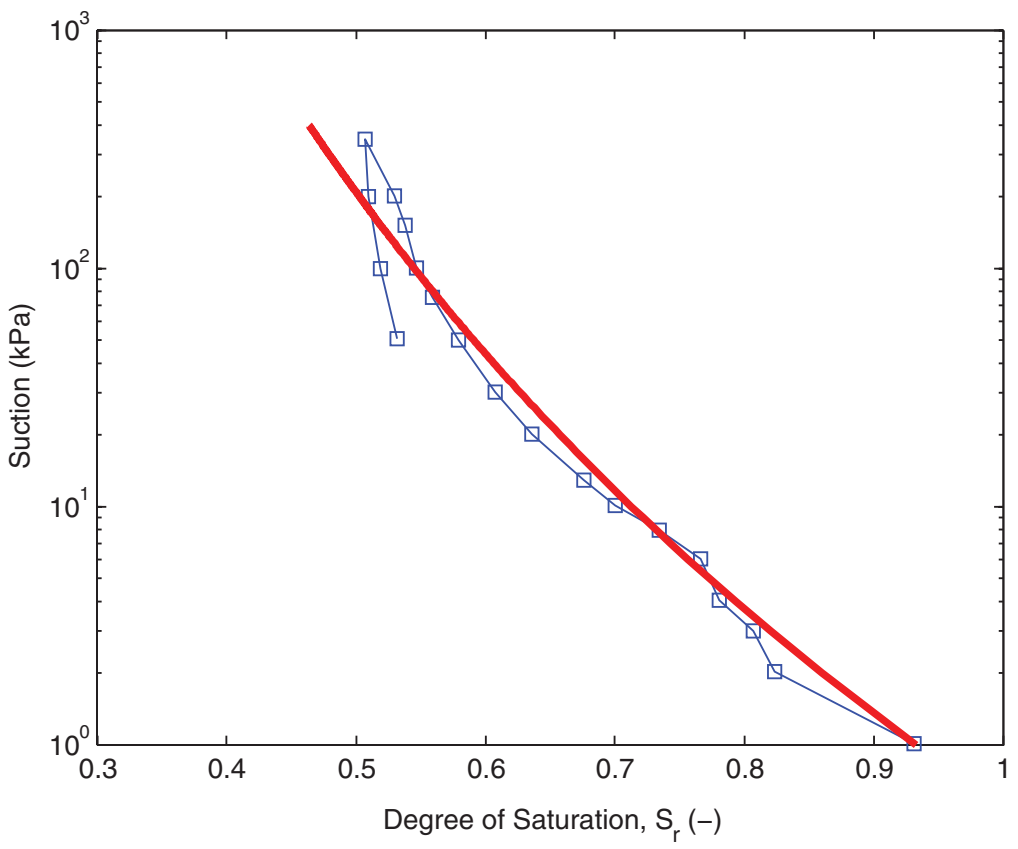

Fig. 10. Water retention curve of residual soil from São Paulo $(8 \mathrm{~m})$ : experimental data from [40] and simulation using Brooks \& Corey's model.

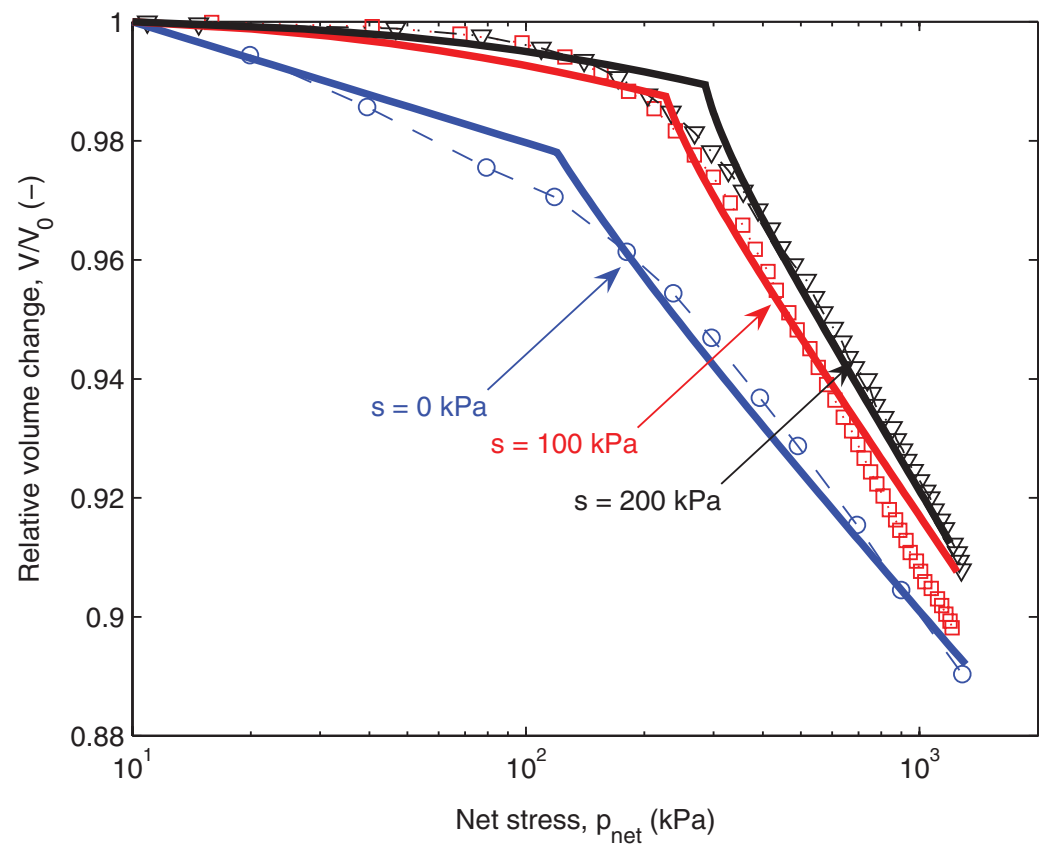

Fig. 11. Isotropic compression of residual soil from São Paulo $(8 \mathrm{~m})$ at different suction values (experimental data from [40]). 


\subsection{Confrontation to experimental results}

Isotropic compression tests performed on specimens (sampled at $8 \mathrm{~m}$ depth) of a residual soil from São Paulo, Brazil (see [40]) are simulated. The main drying branch of the water retention curve has been given by the authors. A good fit is obtained using $s_{e}=0.55 \mathrm{kPa}$ and $\alpha=8.57$ (see Fig. 10). Simulation results using the proposed model are presented in Fig. 11. The model is able to capture the increase in elastic stiffness due to its formulation using an effective stress framework (a higher suction means a higher effective stress and thus a higher bulk stiffness as predicted by Equation (6), see [41, 42] for more details).

A reasonably good prediction can be observed. From this figure, one can see that the proposed model is able to reproduce the maximum of collapse which is typical of natural and compacted unsaturated soils (see among others $[9,43-45])$. This can indeed be seen from the increasing and then decreasing vertical distance between the saturated and any of the unsaturated compression curve in Fig. 11. This feature arises from the chosen coupling between suction and structure contributions to the yield limit (see Equation (17)).

\section{Concluding remarks}

An elastoplastic model extending the Barcelona Basic Model to account for structure of soils and its degradation with deformation has been introduced. It includes coupled phenomena between partial saturation and structure effects. These coupled effects have been modelled to ensure a consistent representation of observed experimental data.

Contrary to various models previously developed, the present model does not account explicitly for a double structure (micro- and macro-porosities). This may be a limitation in terms of modelling capabilities but this strategy has the advantage to provide a model with fewer parameters to fit and which is still able to capture the main features of unsaturated structured soils.

The capabilities of the model have been studied based on a parametric study and satisfactory simulations of the isotropic behaviour of a natural unsaturated soil have been presented. This model is finally able to reproduce the maximum of collapse observed experimentally but impossible to reproduce with BBM-like models.

\section{References}

[1] Terzaghi K. The shearing resistance of saturated soils and the angle between the planes of shear. In: Proc 1st Int Conf Soil Mech Found Engng vol. 1. Cambridge, MA, 1936; pp. 54-56.

[2] Bishop AW. The principle of effective stress. Teknisk Ukeblad. 1959;106(39):859-863.

[3] Jennings JEB, Burland JB. Limitations to the use of effective stresses in partly saturated soils. Géotechnique. 1962;12(2):125-144.

[4] Toll DG. A framework for unsaturated soil behaviour. Géotechnique. 1990;40(1):31-44.

[5] Fredlund DG, Morgenstern NR. Stress State Variables for Unsaturated Soils. Journal of the Geotechnical Engineering Division. 1977;103(5):447-465.

[6] Alonso EE, Gens A, Josa A. A constitutive model for partially saturated soils. Géotechnique. 1990;40(3):405-430.

[7] Wheeler SJ, Sivakumar V. An elasto-plastic critical state framework for unsaturated soil. Géotechnique. 1995;45(1):35-53.

[8] Houlsby GT. The work input to an unsaturated granular material. Géotechnique. 1997;47(1):193-196.

[9] Bolzon G, Schrefler BA, Zienkiewicz OC. Elastoplastic soil constitutive laws generalized to partially saturated states. Géotechnique. 1996;46(2):279-289.

[10] Jommi C. Remarks on the constitutive modelling of unsaturated soils. In: Tarantino A, Mancuso C, editors. Experimental Evidence and Theoretical Approaches in Unsaturated Soils. Proc Int Workshop on Unsaturated Soils. Trento, Italy: Balkema, 2000; pp. 139-154.

[11] Loret B, Khalili N. An effective stress elastic-plastic model for unsaturated porous media. Mech Mater. 2002;34:97-116.

[12] Gallipoli D, Gens A, Sharma R, Vaunat J. An elasto-plastic model for unsaturated soil incorporating the effects of suction and degree of saturation on mechanical behaviour. Géotechnique. 2003;53(1):123-135.

[13] Pereira JM, Wong H, Dubujet P, Dangla P. Adaptation of existing behaviour models to unsaturated states: Application to CJS model. International Journal for Numerical and Analytical Methods in Geomechanics. 2005;29(11):1127-1155.

[14] Russell AR, Khalili N. A unified bounding surface plasticity model for unsaturated soils. Int J Numer Anal Meth Geomech. 2006;30(3):181212.

[15] Khalili N, Geiser F, Blight GE. Effective stress in unsaturated soils: Review with new evidence. Int J Geomech. 2004;4(2):115-126.

[16] Gens A, Sánchez M, Sheng D. On constitutive modelling of unsaturated soils. Acta Geotech. 2006;1(3):137-147.

[17] Nuth M, Laloui L. Effective stress concept in unsaturated soils: Clarification and validation of a unified framework. Int J Numer Anal Meth Geomech. 2008,;32(7):771-801. 
[18] Gallipoli D, Wheeler SJ, Karstunen M. Modelling the variation of degree of saturation in a deformable unsaturated soil. Géotechnique. 2003;53(1):105-112.

[19] Li XS. Modelling of hysteresis response for arbitrary wetting/drying paths. Computers and Geotechnics. 2005;32:133-137.

[20] Wheeler SJ, Sharma RS, Buisson MSR. Coupling of hydraulic hysteresis and stress-strain behaviour in unsaturated soils. Géotechnique. 2003;53(1):41-54.

[21] Leroueil S, Vaughan PR. The general and congruent effects of structure in natural soils and weak rocks. Géotechnique. 1990;40:467-488.

[22] Gens A, Nova R. Conceptual bases for a constitutive model for bonded soils and weak rocks. In: Geomechanical Engineering of Hards Soils-Soft Rocks. Athens. vol. 1. Rotterdam: Balkema, 1993. pp. 485-494.

[23] Liu MD, Carter JP. Modelling the destructuring of soils during virgin compression. Géotechnique. 2000;50(4):479-483.

[24] Rouainia M, Muir Wood D. A kinematic hardening constitutive model for natural clays with loss of structure. Géotechnique. 2000;50(2):153-164.

[25] Kavvadas KM, Amorosi A. A constitutive model for structured soils. Géotechnique. 2000;50(3):263-273.

[26] Baudet B, Stallebrass S. A constitutive model for structured clays. Géotechnique. 2004;54(4):269-278.

[27] Alonso EE, Gens A. Keynote lecture: On the mechanical behaviour of arid soils. In: Proc First Int Symp Engineering Characteristics of Arid Soils. London, 1994; pp. 173-205.

[28] Leroueil S, Barbosa A. Combined effect of fabric, bonding and partial saturation on yielding of soils. In: Proc Asian Conf Unsaturated Soils. Singapore, 2000; pp. 527-532.

[29] Alonso EE, Alcoverro J. Swelling and degradation of argillaceous rocks. In: Keynote Address in the Proceedings of the Third Unsaturated Soils Conference. vol. 3, 2002.

[30] Vaunat J, Gens A. Bond degradation and irreversible strains in soft argillaceous rock. In: GmbH VG, editor. Proceedings of the 12th Panamerican Conference on Soil Mechanics and Geotechnical Engineering, 2003; pp. 479-484.

[31] Pinyol NM, Vaunat J, Alonso EE. A constitutive model for soft clayey rocks that includes weathering effects. Géotechnique. 2007;57(2):137151.

[32] Rouainia M, Pereira JM. A constitutive model for unsaturated soils with structure degradation. In: 8th World Congress of Computational Mechanics, WCCM8. Italy, 2008.

[33] Koliji A, Vulliet L, Laloui L. New basis for constitutive modelling of unsaturated aggregated soil with structure degradation, 2008; pp. 641-646.

[34] Buscarnera G, Nova R. An elastoplastic strainhardening model for soil allowing for hydraulic bonding-debonding effects. International Journal for Numerical and Analytical Methods in Geomechanics. 2009;33(8):1055-1086.

[35] Yang C, Cui YJ, Pereira JM, Huang MS. A constitutive model for unsaturated cemented soils under cyclic loading. Computers and Geotechnics. 2008;35(6):853-859.

[36] Coussy O, Dangla P. Approche énergétique du comportement des sols non saturés. In: Coussy O, Fleureau JM, editors. Mécanique des sols non saturés. Paris: Lavoisier, 2002.

[37] Dangla P. Plasticité et hystérésis. In: Coussy O, Fleureau JM, editors. Mécanique des sols non saturés. Paris: Lavoisier, 2002.

[38] Tamagnini R. An extended Cam-clay model for unsaturated soils with hydraulic hysteresis. Géotechnique. 2004;54(3):223-228.

[39] Brooks RN, Corey AT. Hydraulic properties of porous media. Colorado State University Hydrology Paper. 1964;3:27 pp.

[40] Machado SL, Vilar OM. Geotechnical characteristics of an unsaturated soil deposit at Sao Carlos, Brazil. In: Tan TS, Phoon KK, Hight DW, Leroueil S, editors. Proc Int Workshop on Characterisation and Engineering Properties of Natural Soils. vol. 2. Singapore, 2003; pp. 1305-1321.

[41] Pereira JM, Wong H, Dubujet P. A general framework for constitutive models adaptation to unsaturated states. In: Di Benedetto H, Doanh T, Geoffroy H, Sauzéat C, editors. Deformation Characteristics of Geomaterials, IS-Lyon03. Lyon, France: Balkema, 2003; pp. $1269-1276$.

[42] Alonso EE, Pereira JM, Vaunat J, Olivella S. A microstructurally based effective stress for unsaturated soils. Géotechnique. 2010;60(12):913-925. Available from: http://www.icevirtuallibrary.com/content/article/10.1680/geot.8. p.002.

[43] Muñoz Castelblanco JA, Delage P, Pereira JM, Cui YJ. Some aspects of the compression and collapse behaviour of an unsaturated natural loess. Géotechnique Letters. 2011;1(April-June):17-22.

[44] Della Vecchia G, Jommi C, Romero E. A fully coupled elastic-plastic hydromechanical model for compacted soils accounting for clay activity. International Journal for Numerical and Analytical Methods in Geomechanics. 2012.

[45] Georgiadis K, Potts DM, Zdravkovic L. Three-Dimensional Constitutive Model for Partially and Fully Saturated Soils. International Journal of Geomechanics. 2005;5(3):244-255.

[46] Arroyo M, Amaral MF, Romero E, da Fonseca AV. Isotropic yielding of unsaturated cemented silty sand. Canadian Geotechnical Journal. 2013. 